\title{
AN ECOLOGICALLY-BASED APPROACH TO THE DESIGN OF INTERCROP AGROECOSYSTEMS: AN INTERCROPPING SYSTEM OF SOYBEANS AND TOMATOES IN SOUTHERN MICHIGAN
}

\author{
JOHN VANDERMEER, ROBERT AMBROSE, MICHAEL HANSEN, \\ HUGH McGUINNESS, IVETTE PERFECTO, CRUZ PHILLIPS, PETER ROSSET and \\ BRIAN SCHULTZ
}

Division of Biological Sciences, University of Michigan, Ann Arbor, MI 48109 (U.S.A.)

(Accepted for publication 2 August 1984)

\begin{abstract}
Vandermeer, J., Ambrose, R., Hansen, M., McGuinness, H., Perfecto, I., Phillips, C., Rosset, P. and Schultz, B., 1984. An ecologically-based approach to the design of intercrop agroecosystems: an intercropping system of soybeans and tomatoes in southern Michigan. Ecol. Modelling, 25: 121-150.
\end{abstract}

A model is developed in which the elementary structure of plant competition is translated into the classical yield-density equation. Using the same reasoning, an interspecific form of the model is formulated to predict yielding patterns of intercrops. An experimental system of a tomato/soybean intercrop in southern Michigan was used to test the model. While the fit of the data to the model is generally good, the deviations were sufficiently systematic to suggest several modifications. Augmenting the model to account for spatial variability in the interspecific competitive effect, an excellent fit to experimental results was obtained. The results suggest that a theoretical approach involving plant interactions at the demographic level will be useful in a program of evaluating intercrop designs.

\section{INTRODUCTION}

A central focus of ecology for the past 10 years has been the question of coexistence of species: Why is it that certain species commonly occur together while others exclude one another (MacArthur, 1972; Pianka, 1976)? This problem has been formulated in a variety of ways, some quite complex and esoteric, but all ultimately tried to answering the basic questions of how and why species coexist.

A similar but mainly independent orientation can be seen in agronomic research on intercropping. The basic question is whether or not an intercrop 
produces a yield advantage relative to monocultures (Kass, 1978; Willey, 1979).

Thus we have two questions being asked independently:

(1) Under what conditions will two species coexist?

(2) Under what conditions will two crop types produce more in combination with one another than when separated from each other?

The two questions have obvious similarities, and in certain mathematical interpretations are formally identical (Vandermeer, 1981). It seems reasonable, then, to apply the large body of experimental and theoretical results obtained in work on species coexistence to the practical necessity of intercropping.

The long history of coeistence research in ecology has centered on what is usually referred to as the competitive exclusion principle, originally formulated by Gause (1934). The principle is, loosely, no two species can occupy the same niche. Later popularized (Hardin, 1960) and experimentally studied (Colwell and Fuentes, 1975), the principle simply states that if the competitive interactions between two species are sufficiently weak, the two species will coexist indefinitely. The principle has been extended in various forms to multiple-species situations (Levins, 1968; Vandermeer, 1970; Case and Gilpin, 1974; May, 1974; Case and Casten, 1979). One of its potential applications to agriculture has already been noted (Vandermeer, 1981).

Recent reviews of intercropping (Kass, 1978; Trenbath, 1974; ASA, 1976; Willey, 1979) summarize an impressively large number of empirical studies (78 in Kass, 1978 and 92 in Willey, 1979). While a majority of those studies are from tropical regions, many were done in the temperate zone. Especially popular in the early 1900's were studies of corn-bean (including soybean) intercrops (Etheridge and Holm, 1924; Brown, 1935), and recently vegetable intercropping research has become more common (Cunard, 1976; Bach, 1979; Schultz et al., 1982). In contrast to the relatively small amount of intercropping research in the U.S.A., visitors to China report a wide variety of intercropping experiments in progress in China's temperate regions (Hansen and Risch, 1979; S. Risch, University of California, personal communication, 1984). Attempts at formulating ecological theory associated with intercropping have been rare (Vandermeer, 1981, 1984b; see also introductions in Kass, 1978; Willey, 1979).

In the present work we begin by casting the classic yield-density equation in a form which reveals its underlying ecological meaning. Then, using this underlying ecological rationale, we extend the classical approach to the two-species situation, thereby proposing an ecologically-based theory of intercropping. Finally we use an experimental system of tomatoes and soybeans to investigate the validity of the theory. 
THEORY

It is a well-accepted fact that the yield of a plant population is related to the inverse of its population density. In particular, the equation:

$w^{\theta}=\frac{1}{A+B D}$

seems to be recognized by most workers as an excellent description of the yield-density relation for most known plant populations (Shinozaki and Kira, 1957; Bleasdale and Nelder, 1960; Holliday, 1960). In equation 1, $w$ is the biomass yield of an individual plant, $D$ is the density of the population and the three constants $A, B$ and $\theta$ refer to various biological functions, as described below. The yield of the population as a whole is then, $Y$, defined as:

$$
Y=w D=\frac{D}{(A+B D)^{1 / \theta}}
$$

For purposes of explanation we begin by letting $\theta=1$. Equation 1 can then be written as:

$w=\frac{1}{A}-\frac{B}{A} D w$

We can maximize the yield of an individual plant, theoretically, by setting the population density equal to zero. Thus:

$k=w_{\max }=\frac{1}{A}$

where $k$ thus stands for the maximum yield attainable for an individual plant. If $1 / A$ is the theoretically maximum value, equation 2 further suggests that $(B / A) D w$ is the competitive effect felt by an individual plant. It also must be the case that $(B / A) D$ is the competitive effect, (per-unit-biomass), and $(B / A) w$ is the competitive effect per individual. Thus $B / A$ could be called a competition coefficient.

Looking at the same phenomenon from a slightly different perspective, the competitive effect felt by one particular plant must be the sum of the competitive pressures exerted by all of that plant's neighbors. Furthermore, the intensity of the effect is likely to be proportional to the size of the neighboring individual. In symbols this competitive effect is:

$$
\sum_{i=1}^{N} \alpha w_{i}
$$

where $\alpha$ is the biomass reduction perpetrated by one unit biomass of a 
competitor (the "competition coefficient"), $w_{i}$ is the biomass of the $i$ th individual in the population, and $N$ is the number of individuals which significantly compete with the individual in question.

Thus from one point of view the per unit biomass competitive effect is $\Sigma \alpha$, and from another point of view it is $(B / A) D$, giving:

$$
(B / A) D=\Sigma \alpha
$$

The equivalence of these two expressions is easily seen if we consider further the concept of "the number of individuals which significantly compete". We here follow an approach originally implied in the work of De Wit (1960) and expanded by several authors (e.g. Opie, 1968; Mead, 1971, 1979; Gates et al., 1979; Wixley and Shaw, 1981). Suppose that there exists an area surrounding the plant in question, within which competitive effects are felt from other individuals in the population, and outside of which competitive effects are not felt at all. Obviously we are not suggesting that such an arrangement actually exists in nature, but make these simplifying assumptions only for the purpose of making sense out of the developing theory. If $S$ is the area of the competitively effective region, the number of individuals actually affecting the individual in question must be $N=S D$, where $D$ is the population density. Assuming a uniform population with respect to biomass, we can thus write:

$\sum^{N} \alpha w=\sum^{S D} \alpha w=S D \alpha w$

which by earlier arguments gives us:

$(B / A) D w=S D \alpha w$

and thus

$B / A=S \alpha$

Since $1 / A=k$ we have $B=S \alpha / k$. Thus $B$ is, as suggested earlier, a competition coefficient, albeit not exactly equivalent to the competition coefficient, $\alpha$. Nevertheless, since $S, \alpha$ and $k$ all have intuitive biological meanings, the meaning of $B$ is thus expressed in a biologically meaningful fashion.

Letting $1 / A=k$ and substituting equation 3 into equation 2 , we obtain:

$w=k-\sum \alpha w$

and substituting equation 4 into equation 5 :

$w=k-S D \boldsymbol{\alpha} w$

But equation 6 is meant to represent total plant yield, whereas usually the 
agriculturally significant factor is only a part of the plant, bringing into the picture the general biological rules of how parts of organisms are related to their wholes. The allometric growth law seems to apply in general to both animals and plants (Huxley, 1932; Kira et al., 1956). Thus the yield of the fruit (say) will be related exponentially to the whole plant yield, and we have:

$y=w^{\psi}$

where $y$ is equal to a plant part (the fruits, say). Substituting into 6 and rearranging we have:

$y^{\theta}=\frac{k}{1+S \alpha D}$

which is identical to 1 , with $A=1 / k, \mathrm{~B}-s \alpha / k$, and $\theta=1 / \psi$.

The biological reasoning which yields the intuitively satisfying interpretation of the parameters is actually embodied in equation 5, and partly in equation 7. Equation 5 expresses the simple facts of biological competition, and equation 7 expresses the simple fact of allometric growth. More importantly, such biological reasoning can easily be extended to include another species. Namely, equation 6 can be expressed as:

$w_{1}=k_{1}-S_{11} \alpha_{1} D_{1} w_{1}$

where $w_{1}$ is the biomass of an individual of species number $1, k_{1}$ is the maximum value an individual of species 1 could attain, $S_{11}$ is the critical region for species $1, \alpha_{1}$ is the per unit biomass intraspecific competition coefficient for species 1 , and $D_{1}$ is the population density for species 1 . Several new and obvious parameters come to mind if we are to add a second species. First, there are the obvious parallels to the parameters in equation 7 , $w_{2}, k_{2}, S_{22}, \alpha_{2}$ and $D_{2}$. Second, we must define two other parameters which specifically refer to the interaction between the two species, $S_{12}$ (and its counterpart $S_{21}$ ) and $\beta_{12}$ (and its counterpart $\beta_{21}$ ). While $S_{11}$ refers to an area surrounding an individual of species 1 within which another individual of species 1 will have a competitive effect, $S_{12}$ refers to an area surrounding an individual of species 1 within which an individual of species 2 will have a competitive effect. Similarly, while $\beta_{11}$ refers to the per unit biomass competitive effect of species 1 on species $1, \beta_{12}$ refers to the per unit biomass competitive effect of species 2 on species 1 . With these new definitions we are now prepared to expand equation 7 as:

$$
\begin{aligned}
& w_{1}=k_{1}-S_{11} \alpha_{1} D_{1} w_{1}-S_{12} \beta_{12} D_{2} w_{2} \\
& w_{2}=k_{2}-S_{22} \alpha_{2} D_{2} w_{2}-S_{21} \beta_{21} D_{1} w_{1}
\end{aligned}
$$

These equations represent a model of two plant species interacting, in which the biological reasoning is identical to at least one form of biological 
reasoning that gives rise to the well accepted inverse yield-density equation. Just as equation 6 can be algebraically manipulated to look like equation 1 (with $\theta=1$, that is), so equations 10 can be algebraically manipulated to take the interspecific form of the yield-density relation. For species 1 such manipulation yields:

$$
w_{1}=\frac{k_{1}-\left(k_{2} S_{12} \beta_{12}-k_{1} S_{22} \alpha_{2}\right) D_{2}}{1+S_{11} \alpha_{1} D_{1}+S_{22} \alpha_{2} D_{2}+\left(S_{11} S_{22} \alpha_{1} \alpha_{2}-S_{21} S_{12} \beta_{12} \beta_{21}\right) D_{1} D_{2}}
$$

which can be more compactly written:

$w_{1}=\frac{k_{1}-G_{1} D_{2}}{1+B_{1} D_{1}+B_{2} D_{2}+C D_{1} D_{2}}$

where $G_{1}=\left(k_{2} S_{12} \beta_{12}-k_{1} S_{22} \alpha_{2}\right), \quad B_{i}=S_{i i} \alpha_{i}$, and $C=S_{11} S_{22} \alpha_{1} \alpha_{2}-$ $S_{21} S_{12} \beta_{12} \beta_{21}$. Equation 12 (along with the similar equation for species 2) then represents the interspecific form of the classical inverse yield-density relationship (note the exact equivalence of equations 12 and 1 when $D_{2}$ is set equal to zero - remember $k=1 / A$ ). But once again equation 12 only refers to the yield of a whole plant. If we let $y$ equal a part of the plant we write:

$y_{1}=A w_{1}^{\psi}=\left[\frac{k_{1}-G_{1} D_{2}}{1+B_{1} D_{1}+B_{2} D_{2}+C D_{1} D_{2}}\right]^{\psi}$

and finally, to represent the yield of the entire population:

$$
\begin{aligned}
& Y_{1}=y_{1} D_{1}=\left[\frac{k_{1}-G_{1} G_{2}}{1+B_{1} D_{1}+B_{2} D_{2}+C D_{1} D_{2}}\right]^{\psi} D_{1} \\
& Y_{2}=y_{2} D_{2}=\left[\frac{k_{2}-G_{2} D_{1}}{1+B_{2} D_{2}+B_{1} D_{1}+C D_{1} D_{2}}\right]^{\psi} D_{2}
\end{aligned}
$$

Equations 13, then, represent the ecologically-based model of intercropping. If the model is truly representative of natural processes, it can be used in a variety of ways in developing designs for intercropping systems, a subject to which we return in the discussion. But first it is necessary to determine if the model is in fact capable of representing a natural system.

\section{METHODS}

We chose to work on a system of soybeans and tomatoes. Both are common crops in the midwest, soybean being a low-risk/low-profitability crop and tomato being a high risk/high profitability crop. Putting the two together thus makes a certain amount of economic sense, combining a conservative and gambling approach.

The idea of the experimentation was first to use one series of experiments for estimating parameters. Using the parameter estimates from this first set 


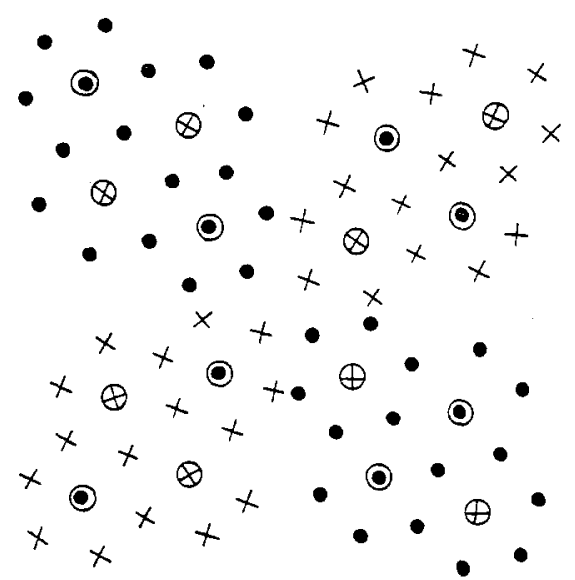

Fig. 1. Basic design unit for beehive experiments. Each $\mathrm{x}$ represents a tomato, each dot a soybean. Circled plants are "center plants", in that they are the principal ones from which data were gathered.

of experiments, the model should be able to predict a set of yields for different density combinations. A second set of experiments then determines whether or not the prediction are valid. The first set of experiments, in which parameters were measured, were beehive experiments (Martin, 1973; Veevers and Boffey, 1975) and the second set were density trails.

A series of spacing experiments, called "beehive" experiments because of their hexagonal shape, were set up for both intra- and interspecific comparisons. In each design unit (Fig. 1) there were 16 plants, eight tomatoes and eight soybeans, that were harvested. These harvested plants are circled in Fig. 1 and are called "center plants" because of their position in the center of a hexagonal arrangement of six other plants. Thus, each design unit contained four center tomato plants surrounded by tomato plants (intraspecific center tomato plants), four center tomato plants surrounded by soybeans (interspecific center tomato plants), four center soybeans surrounded by soybeans (intraspecific center soybeans) and four center soybeans surrounded by tomatoes (interspecific center soybeans).

Each of two blocks contained four design units representing four different interplant distances: $1 \mathrm{~m}, 0.75 \mathrm{~m}, 0.5 \mathrm{~m}$ and $0.25 \mathrm{~m}$. Additionally, each block contained three full monospecific beehive designs, two with soybean at $0.1 \mathrm{~m}$ and $0.01 \mathrm{~m}$ spacing and one with tomatoes at $1.5 \mathrm{~m}$ spacing.

Density trials were set up on an adjacent piece of land. Three densities of soybeans and three densities of tomatoes in a completely crossed design were planted in three blocks of $4 \mathrm{~m} \times 4 \mathrm{~m}$ plots. The three densities of soybeans were: (1) 3-inch * spacing within rows $1 \mathrm{~m}$ apart; (2) 1-inch spacing within

$\overline{* 1 \text { inch }}=25.4 \mathrm{~mm}$. 
rows $1 \mathrm{~m}$ apart; and (3) 1 -inch spacing within rows $0.5 \mathrm{~m}$ apart. The three densities of tomatoes were: (1) $1.5 \mathrm{~m}$ spacing in rows $1.5 \mathrm{~m}$ apart; (2) $1 \mathrm{~m}$ spacing in rows $1 \mathrm{~m}$ apart; and (3) $0.5 \mathrm{~m}$ spacing in rows $1 \mathrm{~m}$ apart.

The beehive experiments and the density trials are shown in an area photo in Fig. 2. Planting, cultivation, and harvesting were identical for both the beehive experiments and the density trials. Soybeans (Asgrow Co.) direct seeded and tomatoes (Heinz 1350) were transplanted on 6 June 1981. Weeding was done by hand weekly. Tomatoes were harvested on 24 August, 5 September, 12 September, 19 September and 26 September. Soybeans were harvested on 9 October.

\section{RESULTS}

The block means of (1) the per-plant yields fore the beehive experiments (Table I) and (2) the block means for the density trials (Table II) are the raw data with which we shall be working in the rest of the paper.

Parameter estimating methods were tailored to the particular parameters. Beginning with $S_{i j}$, the area within which competitive effects are felt, the

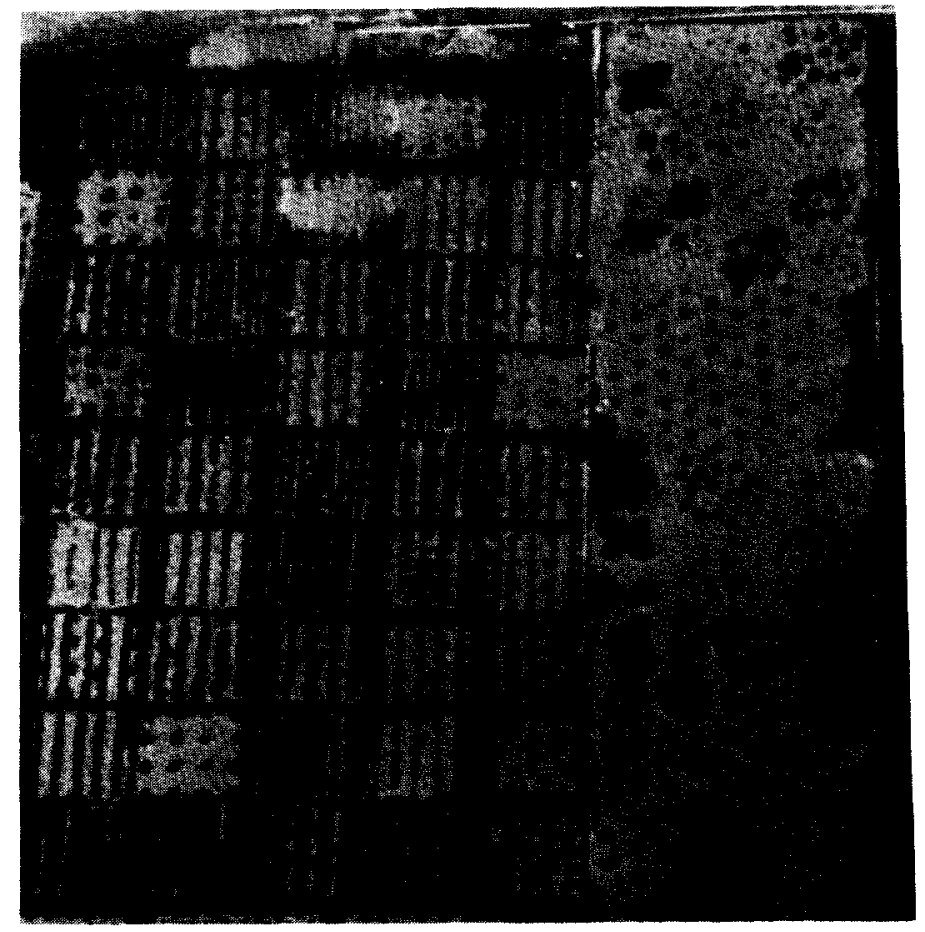

Fig. 2. Aereal photo of study area. Density trials are to the left, beehive experiments to the right. 
data necessary for its computation are plant yields as a function of distance, readily available from the beehive experiments. The yields for the center plants (the circled individuals in Fig. 1) are plotted against the interplant distance (i.e. the surrounding individuals in the hexagon), in Fig. 3a, b, c and d. Also in Fig. 3 are plotted the positions of $S_{i j}$. In some cases the position is at an obvious discontinuity (e.g. Fig. 3d) while in others it is almost arbitrary where the position is located.

Consider in detail the graph of tomato yield against the distance to tomato competitors (Fig. 3a). There is an obvious discontinuity between the 0.5 and 0.75 distances. Thus, the critical distance is $(0.5+0.75) / 2=0.625$, and the critical area $S=\pi(0.625)^{2}=1.227$. The mean yields of the tomatoes at distances less than 0.625 is $1388 \mathrm{~g} / \mathrm{m}^{2}$ (Table I). Because of the experimental design, the exact number of competitors is six. Thus $S D=6$ and equation 9 becomes:

$w=K-6 \alpha w$

TABLE I

Block means for beehive experiments

\begin{tabular}{|c|c|c|c|c|c|c|}
\hline \multirow{3}{*}{$\begin{array}{l}\text { Interplant } \\
\text { distance }(\mathrm{m})\end{array}$} & \multicolumn{6}{|l|}{ Per-plant yield } \\
\hline & \multicolumn{3}{|l|}{ Tomato } & \multicolumn{3}{|l|}{ Soybean } \\
\hline & $\begin{array}{l}\text { Intraspecific } \\
\text { competition }\end{array}$ & $\begin{array}{l}\text { Interspecific } \\
\text { competition }\end{array}$ & Half-hexes & $\begin{array}{l}\text { Intraspecific } \\
\text { competition }\end{array}$ & $\begin{array}{l}\text { Interspecific } \\
\text { competition }\end{array}$ & Half-hexes \\
\hline 1.5 & 9740 & - & - & - & - & - \\
\hline 1.5 & 11860 & - & - & - & - & - \\
\hline 1.0 & 6411 & 9650 & 7112 & 153 & 82 & 140 \\
\hline 1.0 & 6040 & 11096 & 7990 & 105 & 129 & 105 \\
\hline 0.75 & 4919 & 10004 & 6594 & 108 & 54 & 77 \\
\hline 0.75 & 5847 & 8318 & 5778 & 85 & 89 & 112 \\
\hline 0.5 & 1862 & 6127 & 2036 & 58 & 19 & 41 \\
\hline 0.5 & 2150 & 6155 & 2060 & 61 & 22 & 69 \\
\hline 0.25 & 1244 & 2852 & 718 & 15.9 & 1.7 & 11 \\
\hline 0.25 & 298 & 3153 & 645 & 13.9 & 5.2 & 8.9 \\
\hline 0.15 & - & - & - & 5.9 & - & - \\
\hline 0.15 & - & - & - & 5.9 & - & - \\
\hline 0.1 & - & - & - & 4.9 & - & - \\
\hline 0.1 & - & - & - & 1.2 & - & - \\
\hline
\end{tabular}

Each number is a mean of four data points. Intraspecific competition refers to the yield of individual plants surrounded by individuals of their own species, interspecific competition refers to the yield of individual plants surrounded by individuals of the other species, and half-hexes refer to the yield of individual plants surrounded by some individuals of both species. 
130

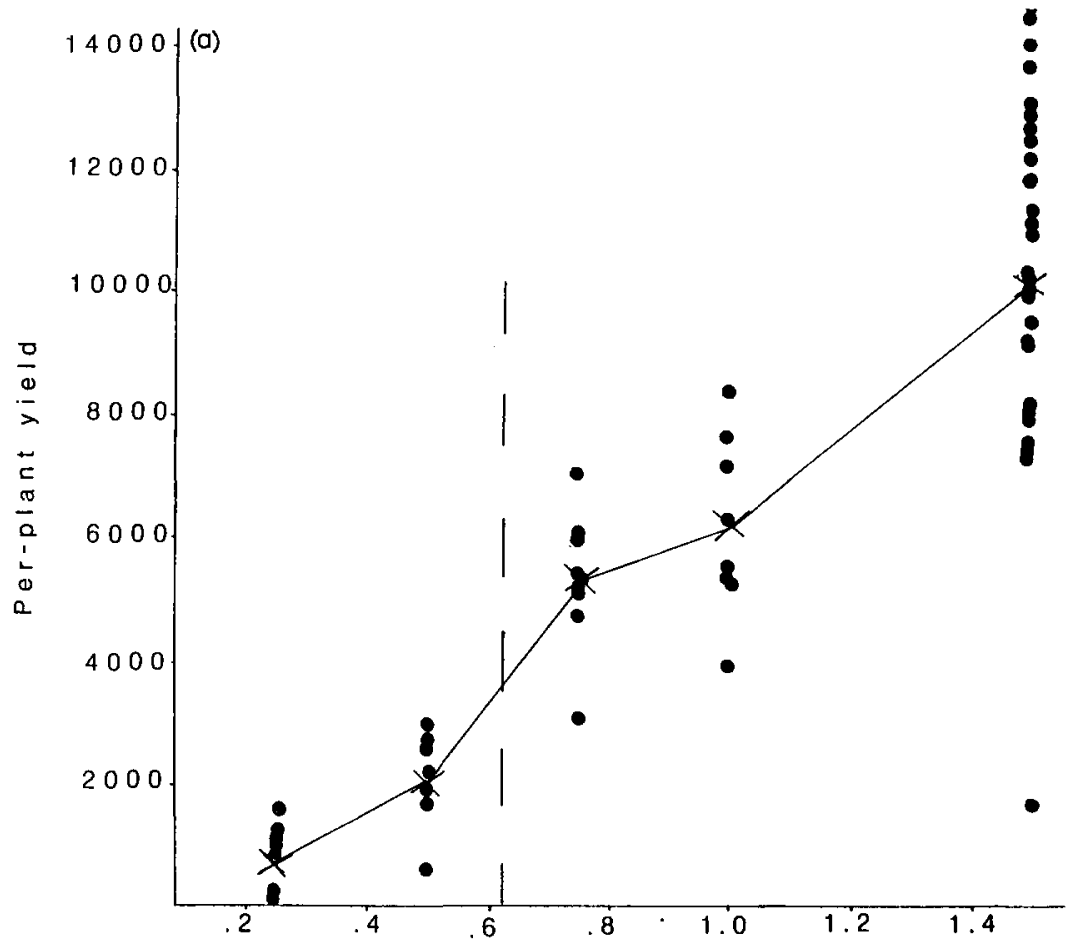

Fig. 3a.

Interplant distance

TABLE II

Yields $\left(\mathrm{g} / \mathrm{m}^{2}\right)$ for density-trial plots

\begin{tabular}{lrrr}
\hline $\begin{array}{l}\text { Density of tomatoes } \\
\left.\text { (per } \mathrm{m}^{2}\right)\end{array}$ & \multicolumn{3}{l}{ Density of soybeans $\left(\right.$ per $\left.\mathrm{m}^{2}\right)$} \\
\cline { 2 - 4 } & 14 & 40 & 80 \\
\hline (a) Yield of tomatoes & 1098 & 870 & 309 \\
0.44 & 1151 & 827 & 385 \\
& 1376 & 1426 & 412 \\
& 2451 & 1704 & 888 \\
1.0 & 3449 & 2766 & 1384 \\
& 3666 & & \\
& 6081 & 3318 & 1249 \\
2.0 & 5576 & 3437 & 3077 \\
& 5005 & 3924 & 1902 \\
(b) Yield of soybeans & & & 178 \\
0.44 & 188 & 269 & 191 \\
& 198 & 146 & 56 \\
& 95 & 174 & 202 \\
1.0 & 179 & 228 & 238 \\
& 202 & 164 & 214 \\
2.0 & 112 & & 209 \\
& 75 & 144 & 132 \\
\hline
\end{tabular}




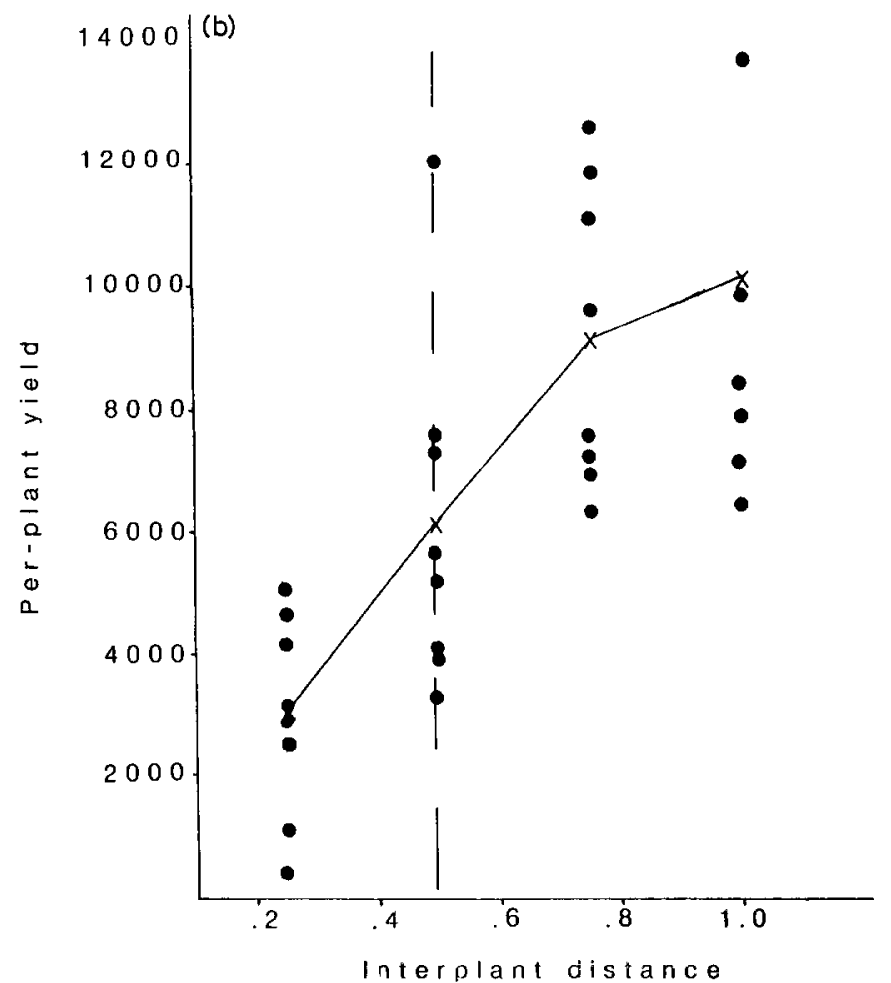

Fig. 3b.

which can be written:

$\alpha_{\mathrm{T}}=\frac{k-w}{6 w}$

The value of $k$ is the average tomato yield in the most highly spaced population, in this case $10,857 \mathrm{~g} / \mathrm{m}^{2}$.

Substituting the above values, we obtain:

$\alpha=\frac{10857-1388}{6(1388)}=1.137$

In a manner equivalent to the estimate of $\alpha_{\mathrm{T}}$, the other $\alpha$ was measured. The estimates of $\beta$ were obtained from modifying equation 10 to make them correspond to the special experimental conditions extant in the beehive experiments. Considering the first of equations 10 , setting $w_{1}=0$ (since all competitors are of species 2 ), we obtain:

$w_{1}=k_{1}-S_{12} \beta_{12} D_{2} w_{2}$

As before, because of the experimental design, $S D=6$, so:

$w_{1}=k_{1}-6 \beta_{12} w_{2}$ 


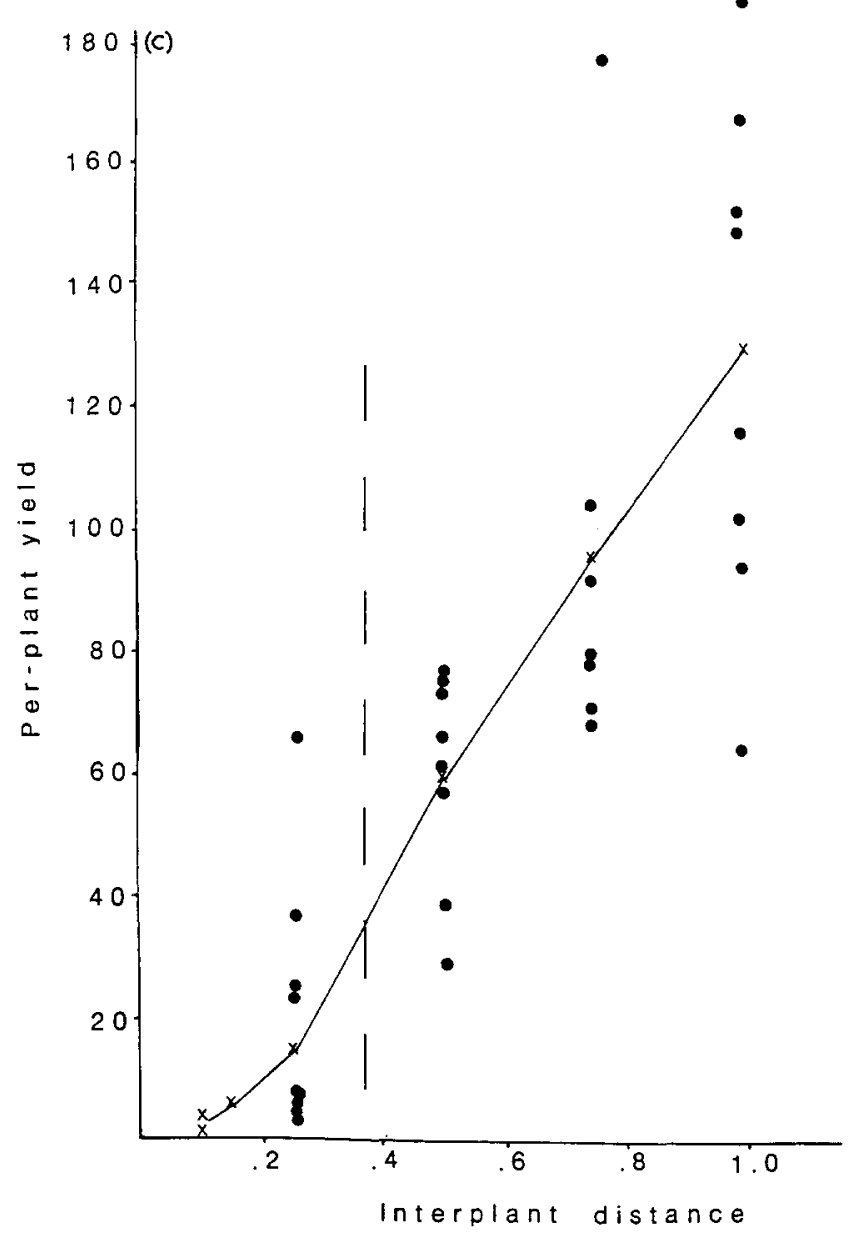

Fig. 3c.

or

$\beta_{12}=\frac{k_{1}-w_{1}}{6 w_{2}}$

as the computing equation. But at this point we must ask which $w_{2}$ should be used in this computing formula. The ultimate goal is to represent the actual degree of competitive effect per unit biomass of competitor. In the beehive experiments the best estimates we have for the individuals perpetrating the competition are the so-called half-hexes, those individuals surrounded by four or five of their own kind and one or two of the other species (see Fig. 1).

Finally the parameters $A$ and $c$ are not estimable from the beehive experiments. To obtain these parameters we utilized the equation:

$Y=A\left(\frac{k D}{1+B D}\right)^{c}$ 


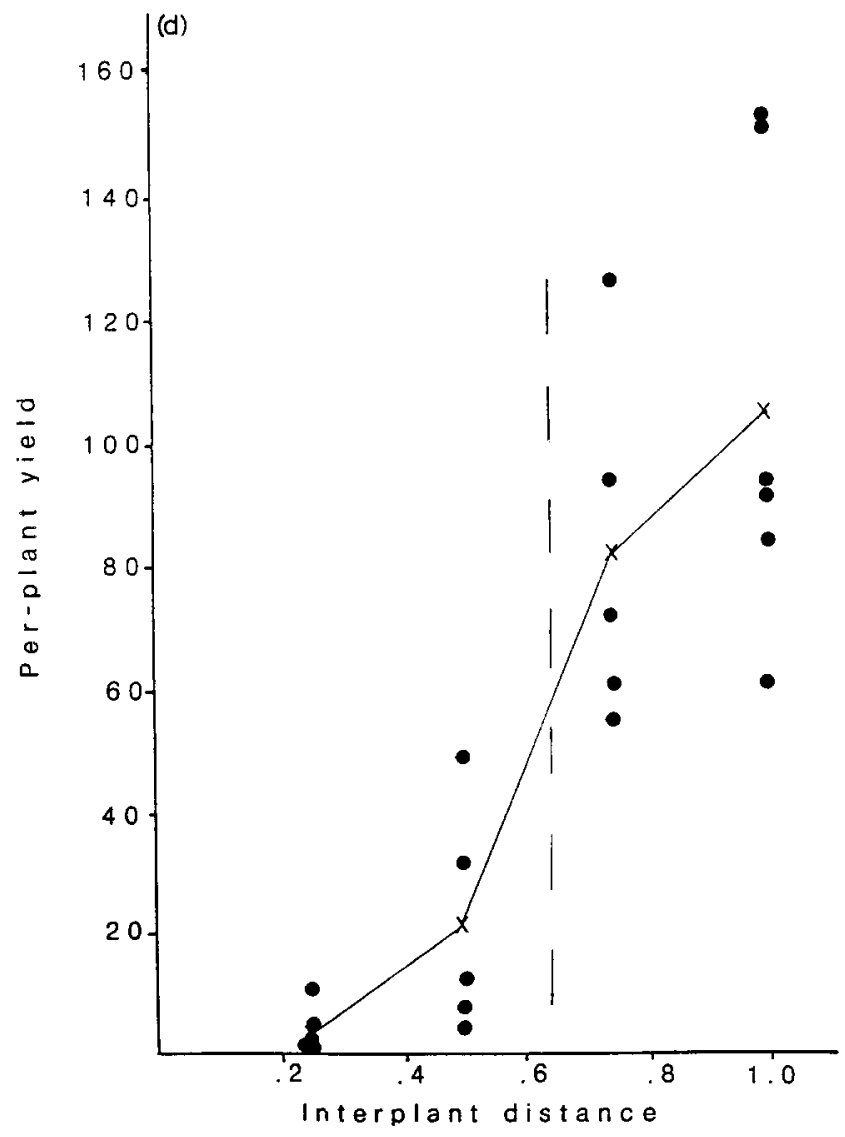

Fig. 3. Per-plant yield as a function of interplant distance from the beehive experiments: (a) tomato yield versus tomato competitors; (b) tomato yield versus soybean competitors; (c) soybean yield versus soybean competitors; (d) soybean yield versus tomato competitors.

\section{TABLE III}

Observed and predicted (based on regression, see text) monoculture yields from density trial experiments

\begin{tabular}{|c|c|c|c|}
\hline \multicolumn{2}{|l|}{ Soybeans } & \multicolumn{2}{|l|}{ Tomatoes } \\
\hline Observed & Predicted & Observed & Predicted \\
\hline$\overline{218}$ & 223 & 4303 & 4520 \\
\hline 226 & 215 & 7168 & 6523 \\
\hline 202 & 208 & 7381 & 7695 \\
\hline
\end{tabular}


(equivalent to equation 8 ) transformed to read:

$\ln Y=\ln A+c \ln \left(\frac{k D}{1+B D}\right)$

to which a linear regression was applied using $Y$ and $D$ from the monocultures of the density trials and the values of $K$ and $B$ as computed from the beehive experiments. The predicted monocultural values, using these parameter estimates are presented in Table III.

A summary of all parameters is displayed in Table IV. Applying the parameter values as shown in Table IV to the interspecific yield-density equations, we solved for tomato and soybean yields for the nine combinations of densities used in the density trials. These values represent predictions which are independent of the interspecific density trial data. That is, the parameters were all estimated from separate experiments, a more rigorous procedure than the more usual method of fitting the equations to the experimental data themselves.

An initial assessment of the model can be made by comparing the residual variance around the model expectation to the total observed variance in the data. The overall variance is $2.5 \times 10^{6}$ and the residual variance is $9.4 \times 10^{5}$. The percentage reduction in variance due to the model as a whole is $62 \%$ ( $F=2.65, P<0.001)$. The overall fit of the model, while not perfect, is at least statistically significant. Such a result is encouraging at a very general level - i.e. we seem to be headed in the right direction - but also suggests that there is considerable room for improvement.

The failure of the model is most noticeable if we examine each crop separately. Computing total and residual variances we have, for soybean, total $=2.9 \times 10^{3}$, residual $3.7 \times 10^{3}(F=0.78$, n.s. $)$, and for tomato, total $=$ $2.7 \times 10^{6}$, residual $=1.9 \times 10^{6}(F=1.30$, n.s. $)$. Thus for tomatoes alone the model accounts for a non-significant $23 \%$ of the variance, while in soybeans the model fails completely. The qualitative performance of the model is diagramatically represented, for tomatoes only, in Fig. 4, where the expecta-

\section{TABLE IV}

Estimates of model parameters

\begin{tabular}{lcc}
\hline Parameter & Tomatoes & Soybeans \\
\hline$K$ & 10860 & 129 \\
$\alpha$ & 1.137 & 3.75 \\
$\beta$ & 120.26 & 0.006 \\
$S_{i i}$ & 1.227 & 0.442 \\
$S_{i j}$ & 0.785 & 1.227 \\
$c$ & 1.15 & 1.0596 \\
$A$ & 0.407 & 2.696 \\
\hline
\end{tabular}


tions from the model are presented as bars and the experimental data as arrowheads. Recall that the model's predictions were made from independent data, not fit to these experimental points. Qualitatively, the model appears to represent the overall trend in the data quite well.

The inefficiency of the model in the case of soybeans is probably mainly a function of the experimental design. In Table $\mathrm{V}$ are the results of three-way analyses of variance for the yields of soybeans and tomatoes. Neither the soybean densities themselves nor the tomato densities had any effect on the soybean yields. This means that, in effect, all the soybean plots were the same and the yield data represent a sample of yields from a single statistical population. This implies that the proper test of the model is to attempt to predict the grand mean of all the soybean yields, since they all come from the same statistical population (see Table Va). The mean value of the nine predicted soybean yields (i.e. from the equations as stipulated by the independent beehive experiments), is $191 \mathrm{~g} / \mathrm{m}^{2}$. The grand mean of the observations is $166 \mathrm{~g} / \mathrm{m}^{2}$. Using a simple $t$-test, the means are not judged statistically different from one another $(P>0.05)$.

Philosophically, the approach taken with the soybeans should also be taken with the tomatoes. If we have no evidence that the various treatments did in fact result in different responses from the plants, they should be

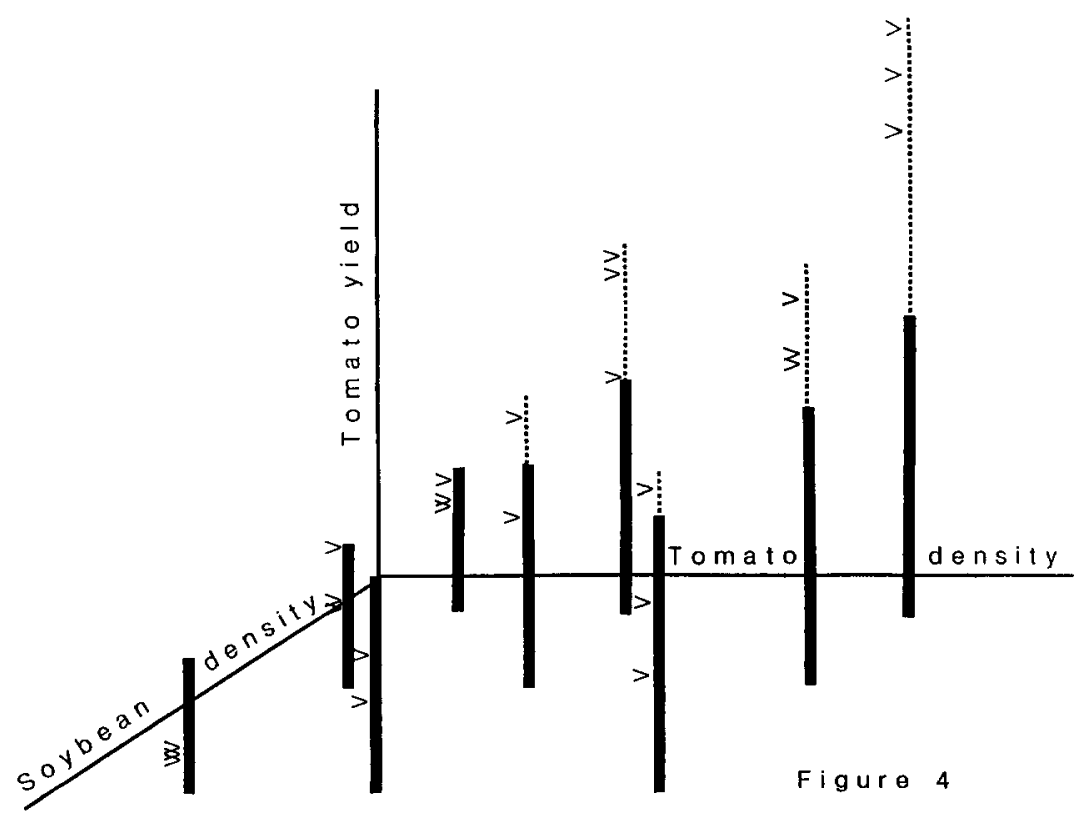

Fig. 4. Diagrammatic representation of the model with tomato yields. Bars are model predictions, arrowheads are experimental data (dotted lines are upward projection of the model predictions to aid the eye). 
lumped. But the simple procedure followed with the soybeans will not work, for, as we see in Table VIb, both the soybean density and the tomato density were significant factors in the experiment. But while the data should not be grouped as a whole, the same principle applies - if various treatment observations do now show statistical evidence of having come from different populations, we should not artificially separate them and attempt to apply a predictive model, at least not a deterministic one.

The mean values of the tomato yields are presented in Fig. 5. As one would expect, a definite pattern is evident, with the low-density tomato (T1) and high-density soybean (S3) giving the lowest yield, and the high-density tomato (T3) and low-density soybean (S1) giving the highest. But more importantly we can recognize five more or less natural groups of treatment means. We have those two groups (each with one mean) already mentioned

\section{TABLE V}

Analysis of variance of yields

\begin{tabular}{lclll}
\hline Source & df & MS & $F$ & Significance \\
\hline (a) Soybean yield & & & & \\
Block & 2 & 0.277 & 2.08 & n.s. \\
Soybean density & 2 & 0.150 & 1.12 & n.s. \\
Tomato density & 2 & 0.270 & 2.03 & n.s. \\
Interaction & 4 & 0.128 & 0.96 & n.s. \\
Error & 14 & 0.133 & & \\
Total & 24 & & & \\
(b) Tomato yield & & & & \\
Block & 2 & 0.132 & 2.49 & n.s. \\
Soybean density & 2 & 5.03 & 94.48 & $P<0.001$ \\
Tomato density & 2 & 2.72 & 51.15 & $P<0.001$ \\
Interaction & 4 & 0.038 & 0.716 & n.s. \\
Error & 14 & 0.053 & & \\
Total & 24 & & & \\
\hline
\end{tabular}

\section{TABLE VI}

Summary statistics for density trials and model predictions

\begin{tabular}{lllll}
\hline Source & $\begin{array}{l}\text { Experimental } \\
\text { variance }\end{array}$ & $\begin{array}{l}\text { Residual } \\
\text { variance }\end{array}$ & $\begin{array}{l}\text { \% Explained } \\
\text { by model }\end{array}$ & $F$ \\
\hline Tomatoes & $2.7 \times 10^{6}$ & $1.9 \times 10^{7}$ & $23 \%$ & 1.30 n.s. \\
Soybeans & $2.9 \times 10^{3}$ & $3.7 \times 10^{3}$ & - & 0.78 n.s. \\
Both crops & $2.5 \times 10^{6}$ & $9.4 \times 10^{5}$ & $62 \%$ & $2.65 \mathrm{p}<0.001$ \\
Grouped & $2.7 \times 10^{6}$ & $1.37 \times 10^{6}$ & $49 \%$ & $1.97 \mathrm{p}<0.05$ \\
tomatoes & & & & \\
\hline
\end{tabular}


(369 and 5554). Then we have three intermediate groups: (1208, 1041, 1136), $(2235,2076)$ and $(3189,3560)$. Statistically, none of the groups contain means that are significantly different from any other mean in the group (using standard $t$-tests). There is some question as to whether the group $(2235,2076)$ is really distinct from $(3189,3560)$. We keep them separate for the analysis, but very little changes if they are pooled.

Using these "natural" groupings, we follow the same procedure as we did with the soybeans. Predicted means within a group of treatments were themselves averaged to obtain a prediction of the pooled mean of the group. These predicted means were then compared to all the observations of all the treatments what were within that group. With this new grouping, considering tomato yields only, the overall variance is again $2.7 \times 10^{6}$ while the residual is $1.37 \times 10^{6}$, for an explained variance of $49 \%(F=1.97, P<0.05)$. Again the model's performance is apparently in the right general direction, but certainly lacks precision. A statistical summary of the model's performance is presented in Table VI.

\section{AN ALTERNATE APPROACH}

The entire previous development relies upon a questionable assumption, that of a critical area around an individual plant within which competition is extant and outside of which competition is not felt at all. A glance at Fig. 3 reveals that this assumption is not even approximately met, not a surprising fact. The assumption was made originally as an intermediate stage in the development of an interspecific form of the yield-density relationship. But

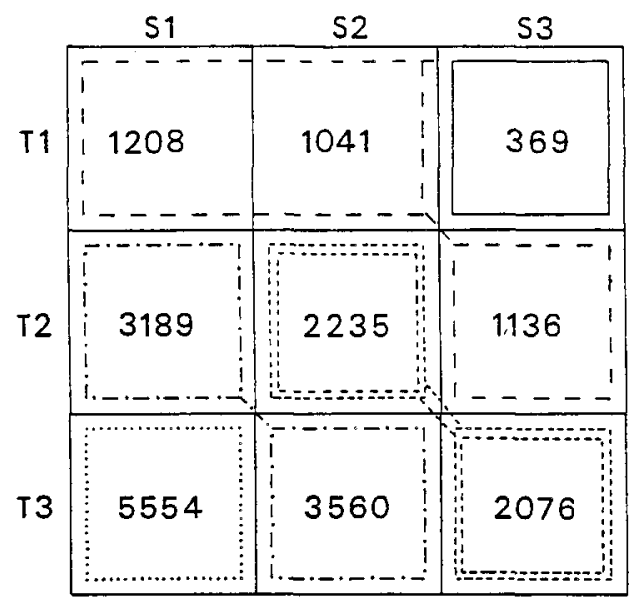

Fig. 5. Grouping of tomato yields. Like means are surrounded by similar symbols. S1, S2, S3 refer to the three densities of soybeans and T1, T2, T3 to those of tomatoes. 

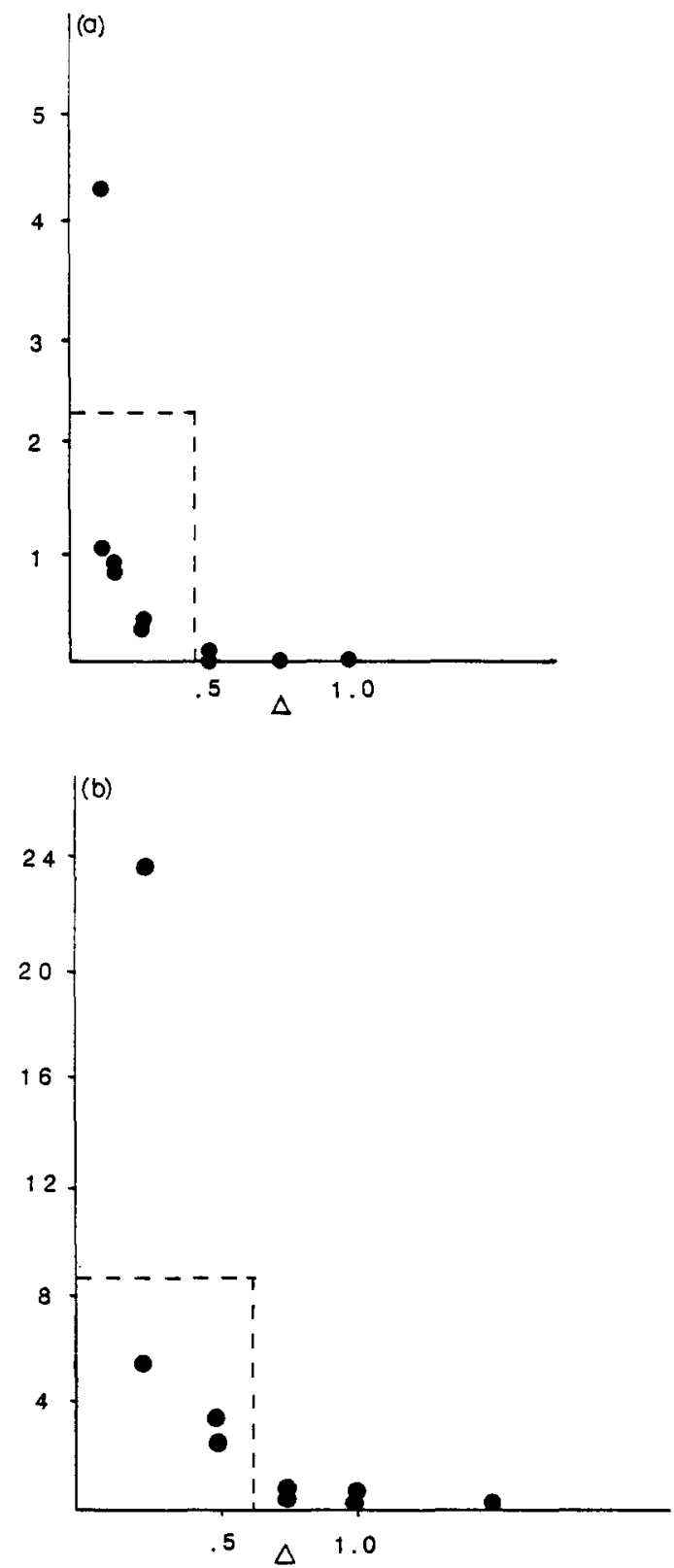

Fig. 6. Competition coefficient as a function of interplant distance. Closed circles are data from beehive experiments, and dotted line indicates approximate position of the expectation under the constant competition hypothesis. (a) Data for soybeans. (b) Data for tomatoes. 
such an assumption is implicit even in the derivation of the well-accepted intraspecific yield-density equation (Vandermeer, 1983). It is, we feel, equally erroneous for the intraspecific case (Fig. 2a, 2c) as it is for the interspecific case (Fig. 2b, 2d).

Looking more closely at the intraspecific data from the beehive experiments, we can modify equation 9 to read:

$\alpha(\Delta)=\frac{k-y(\Delta)}{6 y(\Delta)}$

where $\alpha(\Delta)$, and $y(\Delta)$ are now expressed as functions of the interplant distance. If the constant competition assumption is correct, we would expect $\alpha(\Delta)$ to be some constant value over a range of small $\Delta$, declining precipitously at some critical $\Delta$, and remaining at zero for all larger values of $\Delta$. In Fig. 5 are presented the calculated values of $\alpha(\Delta)$ as a function of $\Delta$, along with the expectations based on the constant competition assumption. As can be readily seen, the expectation is not even approximately met. One might at least expect $\alpha(\Delta)$ to form a convex relationship with $\Delta$, but even this approximate expectation is dramatically violated.

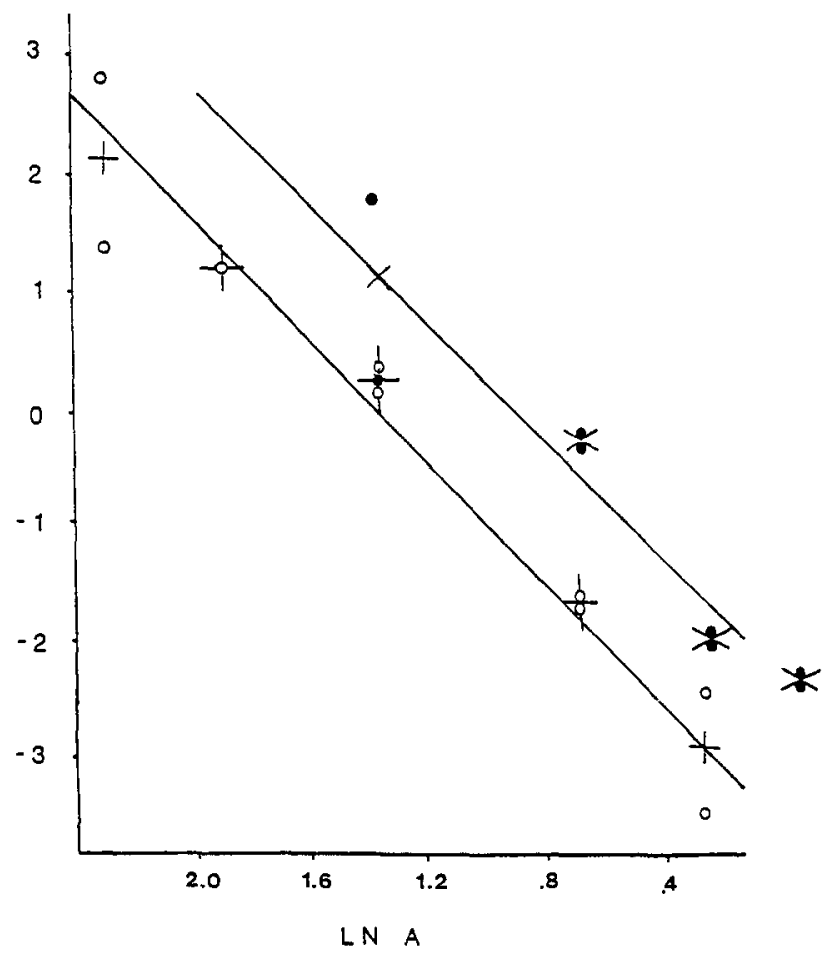

Fig. 7. Log of competition coefficient versus $\log$ of interplant distance. Open circles (data) and crosses (means) indicate soybeans. Closed circles (data) and X's (means) indicate tomatoes. 
The approximate negative exponential appearance of the data in Fig. 6 suggest that the competition coefficient might be related to interplant distance according to the equation:

$\alpha(\Delta)=A \Delta^{b}$

In fact a plot of $\ln \alpha(\Delta)$ againse $\ln \Delta$ yields an almost perfect linear relationship for our intraspecific beehive data (Fig. 7). Since on the average,

$D=\frac{1}{\Delta^{2}}$

equation 14 can be transformed to:

$\alpha(D)=A D^{h / 2}=A D^{c}$

where $c=b / 2$. Equations 14 and 15 describe the process of competition and how it relates to inter-plant distance, and, by implication, density. The parameter $A$ refers to the overall intensity of competition (formally to the value of the competition coefficient when $D$ is equal to 1 ), and the parameter $c$ refers to the rate at which competitive intensity decays as a function of interplant distance (or, to be precise, one-half that rate, since $c=b / 2$ ).

Recalling the earlier development, from equation 6 , it is evident that the current $\alpha(D)$ is equivalent to the $\mathrm{SD} \alpha$ of equation 6 . Thus the analogue of equation 6 , using the density-dependent or "variable competition" hypothesis, is:

$w=k-\alpha(D) w$

Substituting from equation 15 we obtain:

$w=k-A D^{c} w$

which, after rearrangement becomes:

$w=\frac{k}{1+A D^{c}}$

Equation 16 is quite similar to equation 1 , and is actually only a minor variant of the original form as proposed by Bleasdale and Nelder (1960). Watkinson (1980) has already shown how this form results from a slight change in analytical procedure applied to Bleasdale and Nedler's original equation. Mathematically, the two equations are almost identical, with only minor differences occurring at very low densities. But, most importantly, the interpretation of the parameters is very different in the two cases. In the original equation (equation 1) the exponent was interpreted as an allometric growth constant. Its analogue (in equation 16) is the rate of decay of competition. While the interpretation of the other parameters in the equation is the same for both hypotheses (constant versus variable competition), this 
one parameter is dramatically different in the two different cases (Vandermeer, 1984a).

Perhaps a simple difference in biological interpretation does not matter much in a case, such as this, where the analytical forms of the two alternatives are so similar. But the difference becomes extremely critical when we move to the interspecific case, as evidenced below.

We approach the interspecific case, using the variable competition hypothesis, by writing the alternative form of equations 10 (remembering that in general $\alpha(D)=S D \alpha$ or $\beta(D)=S D \beta)$. Such equations are:

$w_{1}=k_{1}-\alpha_{11}\left(D_{1}\right) w_{1}-\beta_{12}\left(D_{2}\right) w_{2}$

$w_{2}=k_{2}-\alpha_{21}\left(D_{1}\right) w_{1}-\beta_{22}\left(D_{2}\right) w_{2}$

The general form of $\alpha$ is, by assumption (and from the appearance of our data as described above), $\alpha=A D^{c}$, whence we may write:

$w_{1}=k_{1}-A_{11} D_{1}^{c_{11}} w_{1}-A_{12} D_{2}^{c_{12}} w_{2}$

$w_{2}=k_{2}-A_{21} D_{1}^{c_{21}} w_{1}-A_{22} D_{2}^{c_{22}} w_{2}$

Again performing the necessary algebraic manipulations to put these equations in proper yield/density form, we obtain, for species 1 :

$w_{1}=\frac{k_{1}-\left(k_{2} A_{12} D_{2}^{c_{12}}-k_{1} A_{22} D_{2}^{c_{22}}\right)}{1+A_{11} D_{1}^{c_{11}}+A_{22} D_{2}^{c_{22}}+A_{11} A_{22} D_{1}^{c_{11}} D_{2}^{c_{22}}-A_{12} A_{21} D_{2}^{c_{12}} D_{1}^{c_{21}}}$

Unlike the single-species case, equation 19 is not analytically similar to equations 13. Furthermore, it is considerably more complicated than the previous model, with the proliferation of four parameters $\left(c_{11}, c_{12}, c_{21}, c_{22}\right)$ where one $(\psi)$ sufficed earlier. Nevertheless, we feel it is probably an important improvement over the initial model — which, it should be recalled, was nothing more than the interspecific form of the classic "reciprocal" yield-density equation. First, while the fit of the data to the constant competition model suggested that the general approach was appropriate, it also suggested that there was room for improvement. Second, a close examination of the assumption of constancy led to a reformulation of one basic idea (changing the constant competition to variable competition) which in turn led to the more complicated model. We now turn to an initial empirical examination of the new model.

\section{A TEST OF THE VARIABLE COMPETITION HYPOTHESIS}

Since the new model arises directly from our attempt at fitting the old model to actual data, we can hardly evaluate the new model with those very same data. Such a procedure would be suspect philosophically, but, more 
important here, would be impossible since the experiments were constructed in such a way that their direct application to the new model is physically impossible. Consequently the present section is merely an attempt to show that the new model holds promise, that it is at least consistent with the data at hand.

The new theoretical equation is given as:

$y=k-\alpha(D) y$

But because of the manner in which the experiments were set up (i.e. a total of six competitors, regardless of $\Delta$ ), the computation equation must be:

$y=k-a(D) S(D) D y$

where, for the experiments $S(D) D=6$. Equation 20 is merely a restatement of equation 6, with $a$ and $S$ expressed as functions of $D$. We can estimate $a(D)$ for each experimental inter-plant distance in the beehive experiments. Presuming:

$a(D)=A^{\prime} D^{c^{\prime}}$

(Vandermeer 1984a), we estimate $A^{\prime}$ and $c^{\prime}$ with a linear regression of $\ln a(D)$ versus $D$ where $a(D)$ is computed, as before with the equation:

$a(D)=\frac{k-y}{6 y}$

But the function $S(D)$ remains unknown. We presume the general form: $S(D)=B D^{b}$

and utilize the monocultural density-trial data to compute $B$ and $b$. If $y(D)$ is the empirical yield for the monoculture, we can write:

$y(D)=\frac{k D}{1+A^{\prime} D^{c^{\prime}} S(D) D}$

and for each monoculture we can then compute $S(D)$ :

$S(D)=\frac{k D-y(D)}{A^{\prime} D^{c^{\prime}+1} y(D)}$

A plot of $\ln S(D)$ versus $\ln D$ reveals a linear relationship, suggesting:

$S(D)=B D^{b}$

Thus the values of $\mathrm{B}$ and $\mathrm{b}$ can be computed from the regression of $\ln S(D)$ on $\ln D$.

In Fig. 7 we present the values of $a(D)$ (computed from the intraspecific beehive experiments according to equation 21) as a function of $D$, on a $\log -\log$ plot. As can be readily seen, the relationships are very close to linear. 
Using the parameters $A^{\prime}$ and $c^{\prime}$ as estimated from the beehive data (see Fig. 6) we now turn to the experimental data from the density trial plot, and, using equation 22 , compute $S(D)$ for each of the three monocultural densities. Regressing $\ln S(D)$ against $\ln D$ we obtain estimates of $B$ and $b$ (see equation 23), which allows us then to compute the final parameters as:

$A=A^{\prime} B$

and

$c=c^{\prime}+b+1$

As a check we then use these estimates to predict the monocultural yields from the monospecific yield-density relationship (equation 16). These predictions are shown, along with the monocultural means in Table VII. The correspondence between predicted and observed is excellent.

Turning finally to the interspecific situation, the overall theoretical equation is:

$y_{1}=k_{1}-\alpha_{11}(D) y_{1}-\alpha_{12}\left(D_{2}\right) y_{2}$

Because of the manner in which the beehive experiments were set up (i.e. only the opposite species acted as competitors) the computation equation is: $y_{i}=k_{i}-a_{i j}\left(D_{j}\right) S_{i j}\left(D_{j}\right) D_{j} y_{j}$

where, for the experiments $S_{i j}(D) D_{j}=6$. So from the beehive experiments: $a_{i j}(D)=\frac{K_{i}-y_{i}}{6 y_{j}}$

The function $S_{i j}(D)$ remains unknown, and uncomputable from the beehive experiments. Our experiments were not exactly set up to test the variable competition hypothesis, their purpose being to test the constant competition hypothesis only. Consequently we were left with no method of estimating $S_{i j}(D)$ independent of the interspecific density trials. Nevertheless, so as to see if the new model can be made to fit these experimental data, we used the yields from the density trials to compute the parameters of the $S(D)$ 's.

TABLE VII

\begin{tabular}{|c|c|c|c|c|c|}
\hline \multicolumn{3}{|c|}{$\begin{array}{l}\text { Monoculture soybean yield } \\
\left(\mathrm{g} / \mathrm{m}^{2}\right)\end{array}$} & \multicolumn{3}{|c|}{$\begin{array}{l}\text { Monoculture tomato yield } \\
\left(\mathrm{g} / \mathrm{m}^{2}\right)\end{array}$} \\
\hline Density & Observed & Predicted & Density & Observed & Predicted \\
\hline 14 & 218 & 221 & 0.44 & 4303 & 4305 \\
\hline 40 & 226 & 217 & 1 & 7168 & 7144 \\
\hline 80 & 202 & 211 & 2 & 7381 & 7410 \\
\hline
\end{tabular}




\begin{tabular}{|c|c|c|c|c|c|c|c|}
\hline & & \multicolumn{4}{|l|}{$A_{i j}$} & \multicolumn{2}{|l|}{$c_{i j}$} \\
\hline & & \multicolumn{2}{|c|}{$\begin{array}{l}\text { Perpetrating } \\
\text { competition }\end{array}$} & & & \multicolumn{2}{|c|}{$\begin{array}{l}\text { Perpetrating } \\
\text { competition }\end{array}$} \\
\hline & & tomato & soybean & & & tomato & soybean \\
\hline Receiving & tomato & 0.520 & 20.2 & Receiving & tomato & 1.893 & 1.205 \\
\hline Competition & soybean & 0.012 & 0.394 & Competition & soybean & 1.091 & 1.100 \\
\hline
\end{tabular}

Since fitting a model directly to data is inelegant in the first place, we felt justified in using the inelegant procedure of trial and error in finding the parameters for $S(D)$. Systematically varying each parameter in turn, we located what appears to be the combination of parameters that gives the minimum sum of squared deviations for the yield data from the density trials. These parameters, along with the monospecific parameters are displayed in Table VIII. Using the parameters of Table VIII and the $k$ 's as estimated earlier we solved for the predicted yields for all nine density combinations.

Assessing the fit can be done, as before, by comparing the residual variance around the model predictions to the total observed variance in the

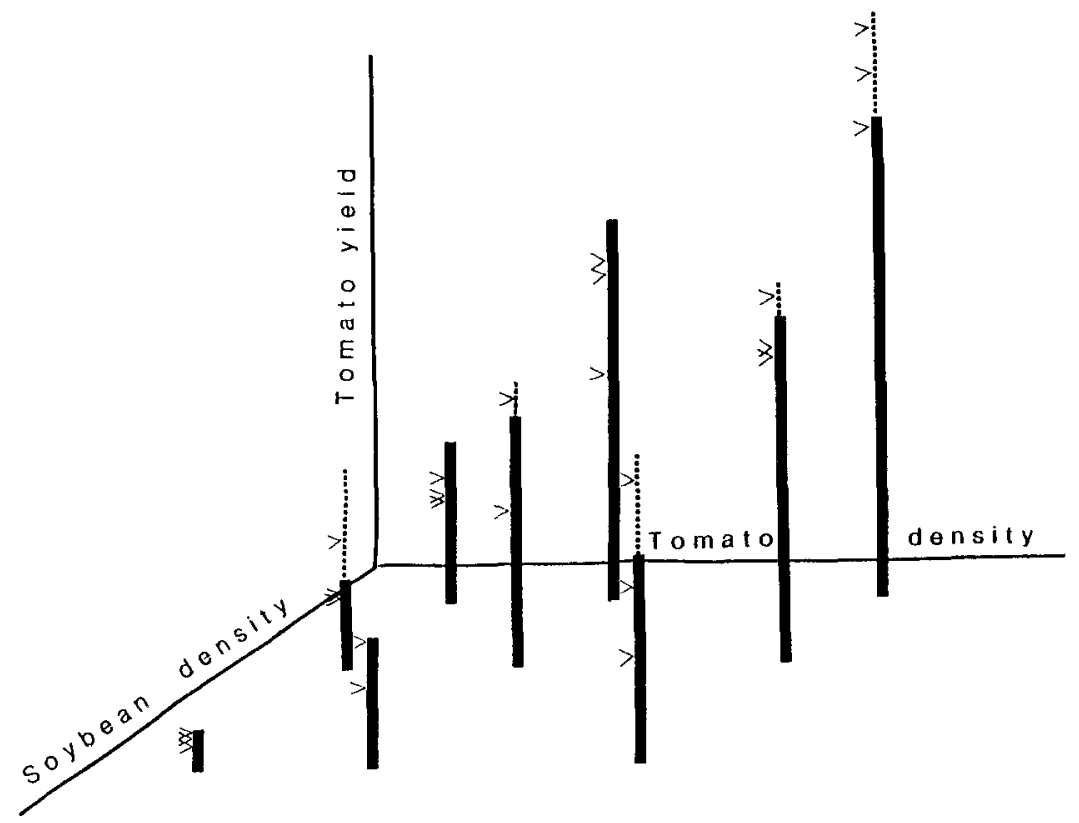

Fig. 8. Diagrammatic representation of the variable competition model. Solid bars indicate the model prediction, arrowheads indicate experimental data (as in Fig. 4). 
data. The overall variance is $2.5 \times 10^{6}$ and the residual variance is $8.8 \times 10^{4}$. The percentage reduction in variance due to the model as a whole is $97 \%$ ( $F=29.7, P<0.001)$. Thus the overall fit of the model is nearly perfect.

Looking at each crop individually, we again see an almost perfect fit of the model. The mean predicted yield for the soybeans is $162 \mathrm{~g} / \mathrm{cm}^{2}$, as compared with the $166 \mathrm{~g} / \mathrm{cm}^{2}$ observed (as before analyzing the variance is pointless since there were no significant differences among any of the treatments (see Table VIa). The overall variance for tomato yields was, as before, $2.7 \times 10^{6}$, and the residual variance $1.8 \times 10^{5}$. The model thus accounts for $93 \%$ of the variance in tomatoes alone $(F=15.34, P<0.001)$.

The qualitative performance of the model is presented diagramatically, for tomatoes, in Fig. 8. The fit is, of course, impressively good. But it bears repeating that the fit is not meant to be a test of the model. It is only presented as evidence that the overall qualities of the model are quite sufficient to represent this data set. A proper test requires an independent estimate of all parameters, as was done for the constant competition hypothesis. At this point we can only say that the model is clearly capable of generating the pattern formed by our data.

\section{SUMMARY AND DISCUSSION}

We have developed a theoretical formulation which derives directly from the classic inverse yield-density equation. In the course of that development we were forced to assume that competitive pressure was constant within a specifiable region surrounding an individual plant, the "constant competition" hypothesis. We then used the system of tomatoes and soybeans to test the constant competition theory. Our results suggested that, while the general approach of a competition-based theory seemed to be in the right direction, the particulars of the theory were in need of substantial revision. In pursuit of possible revisions we examined closely the assumption of constant competition by looking at the estimates of the competition coefficients as a function of inter-plant distance. Rather than the expected pattern of a constant value for low densities followed by a rapid drop to zero, the coefficient varied strongly as a function of interplant distance, even at small distances, suggesting the "variable competition" hypothesis. Based on this new hypothesis we were able to develop a new formulation. Our experimental data on tomatoes and soybeans were not designed to test this new formulation, thus we were not able to subject it to an equivalently rigorous test as in the constant competition case. Nevertheless we utilized these data to examine the qualitative behavior of the new model. Fitting the model to the experimental data resulted in an excellent fit, substantiating the model's capabilities of reducing data of this sort. A critical empirical test of the 
variable competition hypothesis remains to be undertaken, although the results reported herein are certainly encouraging.

The monoculture equation resulting from the variable competition hypothesis can also be derived from Bleasdale and Nelder's (1960) original equation. This was pointed out by Watkinson (1980), although neither he nor Bleasdale and Nelder offered a biological interpretation of the new equation. More importantly, to our knowledge, no one has previously attempted to use this formulation in an interspecific approach.

The utility of an ecologically-based model is mainly in its potential utility in design. For example, if one wishes to maximize the joint production of tomatoes and soybeans (i.e. maximize the Land Equivalent Ratio (LER), (Willey, 1979a), the model can be used to provide a map of predicted LER's as a function of the densities of both crops. By way of example, we have computed such a map for the variable competition model, with the parameters as displayed in Table VIII. As can be seen in Table IX, the densities 1.0 for tomatoes and 10 for soybeans would give the most efficient utilization of available land area (the meaning of LER). These densities are different from the optimal densities of the monocultures.

More abstractly, an approach that has been suggested elsewhere (Vandermeer, 1984c) is to compute all possible yields from all possible densities. The set of all possible yields is called the "yield set". It is most useful to plot the yields of both crops in the intercrop on a graph of yield of crop 1 vs. yield of crop 2. If we take as an optimizing criterion the maximization of the "Land Equivalent Ratio" (LER), we see that the yield set must be convex if there is to be an intercropping combination that gives a higher LER than a monoculture (Vandermeer, 1984c). In Fig. 8 we present the theoretical yield set for tomatoes and soybeans (based on parameter

\section{TABLE IX}

Land equivalent ratios, as predicted from the variable competition model, for various densities of soybeans and tomatoes

\begin{tabular}{|c|c|c|c|c|}
\hline \multirow{2}{*}{$\begin{array}{l}\text { Tomato } \\
\text { density }\end{array}$} & \multicolumn{4}{|c|}{ Soybean density } \\
\hline & 5 & 10 & 15 & $20^{a}$ \\
\hline 0.5 & 1.058 & 1.098 & 1.096 & 1.086 \\
\hline 1.0 & 1.139 & 1.155 & 1.147 & 1.134 \\
\hline $1.5^{\star}$ & 1.135 & 1.147 & 1.142 & 1.132 \\
\hline 2.0 & 1.093 & 1.108 & 1.107 & 1.100 \\
\hline
\end{tabular}

aptimal density for monoculture.

Note that the optimal densities for the intercrop are substantially different from those of the monocultures (10 and 1.0 as opposed to 20 and 1.5 ). 
estimates from our experiments and computations with equation 19), along with our experimental points.

Using the yield-set approach allows us to easily visualize other optimizing criteria. For example, if we define the Relative Value Total (RVT) as the ratio of the value of the polyculture to the value of the most valuable monoculture, we have:

$\mathrm{RVT}=\frac{P_{1} y_{1}+P_{2} y_{2}}{P_{1} M_{1}}$

where $P_{i}$ is the monetary value of the ith crop in the intercrop, $y_{i}$ is the yield of the $i$ th crop in the intercrop, $M_{i}$ is the yield of the $i$ th crop in monoculture, and crop 1 is the more valuable of the two crops. RVT is a linear function of $y_{1}$ and $y_{2}$ :

$y_{1}=M_{1} \mathrm{RVT}+\frac{M_{1} P_{2} Y_{2}}{P_{1}}$

If we wish to find the densities which maximize RVT, we can do so with ease by using the yield set. By fixing the slope of the function, $M_{1} P_{2} / P_{1}$, at its

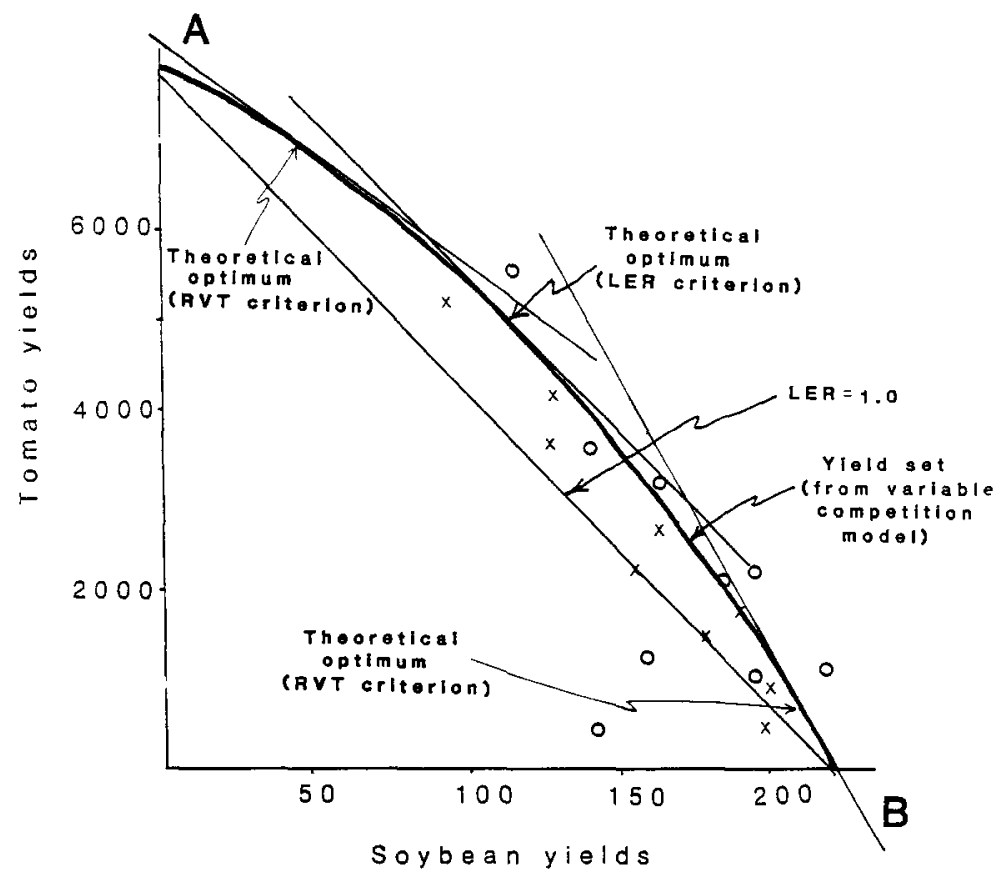

Fig. 9. Yield-set (emphasized curve), experimental data (open circles), and model predictions (X's) based on experimental densities (variable competition model). Various optimality criteria are also displayed (see text). 
actual value, we increase the value of RVT until the function is exactly tangent to the yield set. That point of tangency represents the densities of the two crops which will give the largest monetary value. In Fig. 9 we have illustrated the computation of the maximum value total for two sets of tomato and soybean prices. The line labeled A indicates optimizing RVT when tomato is the most valuable product and the line labeled B indicates optimizing RVT when soybean is the most valuable product. Details of this sort of computation can be found in Schultz et al. (1982) and Vandermeer (1984b).

At the more theoretical level our results raise certain questions about the basic process of plant competition. The reciprocal yield-density equation, apparently today's received theory, seems to require an assumption of constant competitive pressure over a defined region of space. Our data suggest that such an assumption is invalid, that competitive pressure is reduced rapidly as the distance between plants is increased. We suggest that this not very surprising fact should be investigated further.

While the proposition that competitive pressure declines as two plants are located farther apart will hardly generate controversy, a slight extrapolation to other situations might be less palpable to ecologists. Might we apply this same principle to resource gradients? Two individuals located at the same position on a resource gradient might display a certain level of competitive pressure against one another, yet that level might decline rapidly as their separation along the gradient becomes larger.

The approach presented in this paper is rather primitive, at least from the point of view of application. While we feel the general structure of our model is appropriate (i.e. a model based on ecological interactions), much of the detail of the model must be refined with respect to those parameters that are manipulable in the actual agroecosystem. For example, we would eventually wish to be able to predict what would happen as a result of increased urea (say) application. To approach the problem at this level will require detailed theoretical and empirical studies of the three parameters, $k, A$ and $c$ (both intra and interspecifically).

\section{ACKNOWLEDGEMENT}

This work was supported by NSF Grant No. DEB8108271.

\section{REFERENCES}

ASA, 1976. Multiple Cropping. Am. Soc. Agron. Spec. Publ. 27, American Society of Agronomy, Madison WI, 378 pp.

Bach, C.E., 1979. Effects of plant density and diversity on the population cynamics of the striped cucumber beetle, Acalymma vittata. Ph.D. Thesis, University of Michigan, Ann Arbor, MI, $223 \mathrm{pp}$. 
Bleasdale, J.K.A. and Nelder, J.A., 1960. Plant population and crop yield. Nature (London), 188: 342.

Brown, H.B., 1935. Effect of soybeans on corn yields. La. Agric. Exp. Stn. Bull. 265, 31 pp.

Case, T.J. and Casten, R.G., 1979. Global stability and multiple domains of attraction in ecological systems. Am. Nat., 113: 705-714.

Case, T.J. and Gilpin, M.E., 1974. Interference competition and niche theory. Proc. Nat. Acad. Sci., 71: 3073-3077.

Colwell, R.K. and Fuentes, E.R., 1975. Experimental studies of the niche. Annu. Rev. Ecol. Syst., 6: 281-310.

Cunard, A.C., 1976. Interplanting. Res. Dev. Rep. 3, Rodale Press, Emmaus, PA, 43 pp.

De Wit, C.T., 1960. On competition. Versl. Landbouwk. Onderz. Rijkslandbouwproefstns., $66(8), 82 \mathrm{pp}$.

Etheridge, W.C. and Holm, C.A., 1924. Corn and soybeans. Mo. Agric. Stn. Bull. 220, 23 pp.

Gates, D.J., O'Connor, A.J. and Westcott, M., 1979. Partitioning the union of disks in plant competition models. Proc. R. Soc. (London) A, 367: 59-79.

Gause, G.F., 1934. The Struggle for Existence. Hafner, New York, NY, 163 pp.

Hansen, M.K. and Risch, S.J., 1979. Food and agriculture in China: Part I. Sci. People, 13: $39-45$.

Hardin, 1960. The competitive exclusion principle. Science, 131: 1292-1297.

Holliday, R., 1960. Plant population and crop yield. Field Crop Abstr., 13: 159-167; $247-254$.

Huxley, J.S., 1932. Problems of relative growth (2nd Edition, 1972). Mac Veagh, London/ Dover/New York, $276 \mathrm{pp}$.

Kass, D.C.L., 1978. Polyculture cropping systems: review and analysis. Cornell Int. Agric. Bull. 32, 69 pp.

Kira, T., Ogawa, H., Hozumi, K., Koyama, H. and Yoda, K., 1956. Intraspecific competition among higher plants. V. Supplementary notes on the C-D effect. J. Inst. Polytech. Osaka City Univ. Ser. D, 7: 1-14.

Levins, R., 1968. Evolution in Changing Environments. Princeton University Press, Princeton, NJ.

MacArthur, R.H., 1972. Geographical Ecology. Harper and Row, New York, NY.

Martin, F.B., 1973. Beehive designs for observing variety competition. Biometrics, 29: $397-402$.

May, R.M., 1974. Stability and Complexity in Model Ecosystems (2nd Edition). Princeton University Press, Princeton, NJ.

Mead, R., 1971. Models for interplant competition in irregularly distributed populations. In: E.C. Pielou et al. (Editors), Statistical Ecology, Vol. 2. Pennsylvania State University Press, University Park, PA, pp. 13-32.

Mead, R., 1979. Competition experiments. Biometrics, 35: 41-54.

Opie, J.E., 1968. Predictability of individual tree growth using various definitions of competing basal area. For. Sci., 14: 314-323.

Pianka, E.R., 1976. Competition and niche theory. In: R.M. May (Editor), Theoretical Ecology. Saunders, Philadelphia, PA, pp. 114-141.

Schultz, B., Phillips, C., Rosset, P. and Vandermeer, J., 1982. An experiment in intercropping cucumbers and tomatoes in Southern Michigan, U.S.A. Sci. Hortic., 18: 1-8.

Shinozaki, K. and Kira, T., 1956. Intra-specific competition among higher plants. VII. Logistic theory of the C-D effect. J. Inst. Polytech. Osaka City Univ. Ser. D, 7: 35-72.

Trenbath, B.R., 1974. Biomass productivity of mixtures. Adv. Agron., 26: 177-210.

Vandermeer, J.H., 1970. The community matrix and the number of species in a community. Am. Nat., 104: 73-83. 
Vandermeer, J.H., 1981. The interference production principle: an ecological theory for agriculture. Bioscience, 31: 361-364.

Vandermeer, J.H., 1984b. The interpretation and design of intercrop systems involving environmental modification by one of the components: a theoretical framework. J. Biol. Agric. Hortic. (in press).

Vandermeer, J.H., 1984c. Towards an ecological theory for the design of intercrop agroecosystems. Silver Jubilee Symp. Soc. Trop. Ecol. (in press).

Vandermeer, J.H., 1984a. Plant competition and the yield-density relationship. J. Theor. Biol. (in press).

Veevers, A. and Boffey, T.B., 1975. On the existence of leveled beehive designs. Biometrics, 31; 963-967.

Willey, R.W., 1979. Intercropping-its importance and research needs. Field Crop Abstr., 32: $1-10 ; 73-85$.

Wixley, R.A.J. and Shaw, M.J.P., 1981. A model relating yield to individual plant area for predicting growth compensation in Central African field tobacco. Ann. Appl. Biol., 98: $339-346$. 